\title{
Neurohormonal response to left ventricular reconstruction surgery in ischemic cardiomyopathy
}

\author{
Soren Schenk, MD \\ Patrick M. McCarthy, MD a,b,c,d \\ Randall C. Starling, MD, MPH ${ }^{c, d, e}$ \\ Katherine J. Hoercher, $\mathrm{RN}^{\mathrm{b}, \mathrm{c}, \mathrm{d}}$ \\ Melanie D. Hail, BSN ${ }^{\mathrm{c}}$ \\ Yoshio Ootaki, MD, PhD ${ }^{a}$ \\ Gary S. Francis, MD ${ }^{\mathrm{c}, \mathrm{d}, \mathrm{e}}$ \\ Kazuyoshi Doi, MD \\ James B. Young, $\mathrm{MD}^{\mathrm{c}, \mathrm{d}, \mathrm{e}}$ \\ Kiyotaka Fukamachi, MD, PhD
}

See related editorial on page 17.
From the Department of Biomedical Engineering, ${ }^{a}$ Lerner Research Institute, Department of Thoracic and Cardiovascular Surgery, ${ }^{\mathrm{b}}$ George M. and Linda H. Kaufman Center for Heart Failure, ${ }^{\mathrm{c}}$ Transplant Center, ${ }^{\mathrm{d}}$ and Department of Cardiovascular Medicine, ${ }^{\mathrm{e}}$ The Cleveland Clinic Foundation, Cleveland, Ohio.

Supported by the Department of Thoracic and Cardiovascular Surgery and the George M. and Linda H. Kaufman Center for Heart Failure at The Cleveland Clinic Foundation.

Address for reprints: Patrick M. McCarthy, MD, Department of Thoracic and Cardiovascular Surgery/F25, The Cleveland Clinic Foundation, 9500 Euclid Ave, Cleveland, OH 44195 (E-mail: mccartp@ccf.org).

J Thorac Cardiovasc Surg 2004;128:38-43 $0022-5223 / \$ 30.00$

Copyright $\odot 2004$ by The American Association for Thoracic Surgery

doi:10.1016/j.jtcvs.2003.11.012
Objectives: Activation of the neuroendocrine axis in congestive heart failure is of prognostic significance, and neurohumoral blocking therapy prolongs survival. The hypothesis that surgical reduction of left ventricular size and function decreases neuroendocrine activation is less established. We evaluated the neurohormonal response to left ventricular reconstruction surgery in ischemic cardiomyopathy.

Methods: Norepinephrine, plasma renin activity, and angiotensin II were measured in 10 patients before and 12 months after left ventricular reconstruction. In an additional 5 patients, brain natriuretric peptide was measured before and 3 months postoperatively. Three-dimensional cardiovascular imaging was used to assess ejection fraction and left ventricular end-diastolic volume index.

Results: Concurrent with improvements of New York Heart Association functional class $(2.9 \pm 0.5$ preoperatively vs $2.0 \pm 0.4$ postoperatively, $P<.001)$, ejection fraction $(23.9 \% \pm 6.6 \%$ vs $36.2 \% \pm 6.2 \%, P<.01)$, and left ventricular enddiastolic volume index $\left(140.8 \pm 33.8 \mathrm{~mL} / \mathrm{m}^{2}\right.$ vs $\left.90.6 \pm 18.3 \mathrm{~mL} / \mathrm{m}^{2}, P<.01\right)$, considerable reductions were observed for median plasma profiles of norepinephrine $(562.0 \mathrm{pg} / \mathrm{mL}$ vs $319.0 \mathrm{pg} / \mathrm{mL}, P<.05)$, plasma renin activity $(5.75 \mu \mathrm{g} / \mathrm{L} / \mathrm{h}$ vs 3.45 $\mu \mathrm{g} / \mathrm{L} / \mathrm{h}, P<.05)$, angiotensin II $(41.0 \mathrm{ng} / \mathrm{mL}$ vs $23.0 \mathrm{ng} / \mathrm{mL}, P=.051)$, and brain natriuretric peptide $(771.0 \mathrm{pg} / \mathrm{mL}$ vs $266.0 \mathrm{pg} / \mathrm{mL}, P<.05)$. The more plasma renin activity or angiotensin II decreased after left ventricular reconstruction, the higher was the increase in ejection fraction $(R=-.745, P<.05$ [plasma renin activity]; $R=-.808, P<.05$ [angiotensin II]).

Conclusions: Surgical improvements of ejection fraction and left ventricular enddiastolic volume index by left ventricular reconstruction were accompanied by improvement of both the neuroendocrine activity and the functional status in patients with congestive heart failure. Whether this favorable neurohormonal response is predictive of an improved survival requires further evaluation.

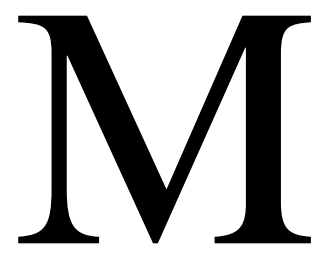

yocardial infarction is a common cause of congestive heart failure $(\mathrm{CHF}) .{ }^{1}$ Following injury, ventricular remodeling ensues, resulting in infarct expansion, left ventricular (LV) enlargement, and occasionally aneurysm formation. ${ }^{2}$ Concomitant activation of neurohumoral systems occurs and is of prognostic importance. ${ }^{3}$ Increased plasma norepinephrine (NE) and plasma renin activity (PRA) are historically associated with poor surviv- 
TABLE 1. Medications $(n=15)$

\begin{tabular}{lrr}
\hline Medication & Preoperative & Postoperative* $^{*}$ \\
\hline Beta-blocker & $12(80 \%)$ & $12(80 \%)$ \\
ACE inhibitor & $14(93 \%)$ & $14(93 \%)$ \\
Diuretic & $10(67 \%)$ & $10(67 \%)$ \\
Spironolactone & $4(27 \%)$ & $6(40 \%)$ \\
Digoxin & $13(87 \%)$ & $8(53 \%)$
\end{tabular}

$A C E$, Angiotensin-converting enzyme.

Data presented as number (\%) of patients.

*Time of postoperative follow-up varied from 3 months (5 patients) to 12 months (10 patients). No difference was observed between groups. Individual dosages of beta-blockers, ACE inhibitors, and diuretics were increased after surgery in 4, 1, and 1 patients, respectively; were decreased in 2, 4, and 4 patients; respectively; and were unchanged in 6,9 , and 5 patients, respectively.

al. ${ }^{4}$ Plasma angiotensin II (A-II) is elevated in patients with CHF. ${ }^{5}$ Plasma brain natriuretric peptide (BNP) is increased in patients with $\mathrm{CHF}$ and also predicts long-term survival after myocardial infarction. ${ }^{6-8}$ Neuroendocrine activation can be altered by neurohumoral blocking therapy (betablockers and angiotensin-converting enzyme [ACE] inhibitors), reducing mortality in $\mathrm{CHF},{ }^{9,10}$

LV reconstruction (LVR) surgery effectively treats CHF due to ischemic cardiomyopathy by removing nonviable, scarred tissue and restoring more normal ventricular geometry. ${ }^{11}$ We hypothesized that surgical intervention would initiate beneficial LV remodeling. If prognosis is improved, there should also be reduced neurohumoral activation. We analyzed the level of neuroendocrine activation before and up to 1 year after LVR surgery and we present the results here.

\section{Materials and Methods Patients}

Plasma levels of NE, PRA, and A-II were measured before (baseline) and 12 months after LVR in 10 patients. Criteria for study enrollment were anticipated LVR surgery judged as previously described, ${ }^{11}$ the agreement to return for all scheduled follow-up visits, and informed consent in compliance with the Institutional Review Board at The Cleveland Clinic Foundation. Three additional patients were originally recruited but could not return to our institution for a follow-up visit because they moved to a remote location. They were omitted from this study. Plasma BNP was measured in 5 additional patients before and 3 months after surgery. All patients ( 7 women, 8 men; age $60.7 \pm 11.8$ years) received optimized medical therapy for heart failure, consisting of ACE inhibitors, beta-blockers, diuretics, spironolactone, and digoxin (Table 1). Blood tests were drawn the same day as either real-time 3-dimensional echocardiography (RT3DE) or magnetic resonance imaging (MRI). We have previously shown that RT3DE and MRI not only accurately reflect the geometry in LV aneurysms but also reproduce $\mathrm{LV}$ volumes and ejection fraction (EF) with excellent correlation and agreement. ${ }^{12,13}$ Pre- and postoperative assessment of LV function by RT3DE and/or MRI was available in
TABLE 2. Surgical details $(n=15)$

\begin{tabular}{lc}
\hline Aneurysm location (anterior/posterior) & $\mathbf{1 5 / 0}$ \\
\hline Wall movement (dyskinetic/akinetic) & $13 / 2$ \\
Primary/patch closure of & $14 / 1$ \\
$\quad$ endoaneurysmorrhaphy & 11 \\
CABG & $2.2 \pm 1.0$ \\
$\quad$ Number of grafts & $73 \%$ \\
Utilization of arterial grafts & 5 \\
Mitral valve repair & 2 \\
Tricuspid valve repair & 2 \\
Cryoablation &
\end{tabular}

$C A B G$, Coronary artery bypass grafting.

Data presented as mean \pm SD or number $(\%)$ of patients.

13 patients; 2 patients had only preoperative cardiovascular imaging.

\section{Surgical Technique}

Normothermic cardiopulmonary bypass was used in all patients. First, adjunct procedures, for example, coronary artery bypass grafting (CABG) and/or repair of the mitral valve (MVR), were performed under cardioplegic arrest. LV reconstruction was performed on the beating heart. ${ }^{14}$ The LV aneurysm was opened and adherent thrombi were removed. Any subendocardial scar on the septum and anterior LV wall was resected, and the border zone between infarcted and normal myocardium was identified. Two circular polypropylene purse-string sutures were placed, creating a neck and obliterating the orifice. The ventriculotomy was closed by a horizontal mattress suture. Intraoperative echocardiography was used to assess the appropriate LV cavity size. ${ }^{15}$ Surgical details are summarized in Table 2.

\section{Quantitative 3-Dimensional Imaging}

An RT3DE system (Volumetrics Medical Imaging, Inc, Durham, NC) or MRI (Siemens Vision, Erlangen, Germany) was used to determine LV end-diastolic (LVEDV) and end-systolic (LVESV) volumes $^{13,16}$ and to calculate EF, LVEDV index (LVEDVI), and LVESV index (LVESVI).

\section{Neurohormone Assays}

Venous blood samples were obtained with the patient in the supine position after 30 minutes of rest and immediately transferred to chilled tubes. NE (normal range $80-520 \mathrm{pg} / \mathrm{mL}$ ), PRA (normal range $0.5-1.8 \mu \mathrm{g} / \mathrm{L} / \mathrm{h}$ ), and $\mathrm{BNP}$ (normal range $<100 \mathrm{pg} / \mathrm{mL}$ ) were measured at our institution; additional probes were sent on dried ice to Quest Diagnostics (San Juan Capistrano, Calif) for measurement of A-II (normal range 10-50 ng/L).

\section{Statistical Analysis}

Data were expressed as median, mean, and 95\% confidence interval. Neurohormones, cardiovascular function, and New York Heart Association (NYHA) functional class were compared by a Wilcoxon signed-rank test. The association between neurohormones and LV function was evaluated by Pearson's correlation test. All analyses were performed with SPSS 11.5 (SPSS Inc, Chicago, Ill). 


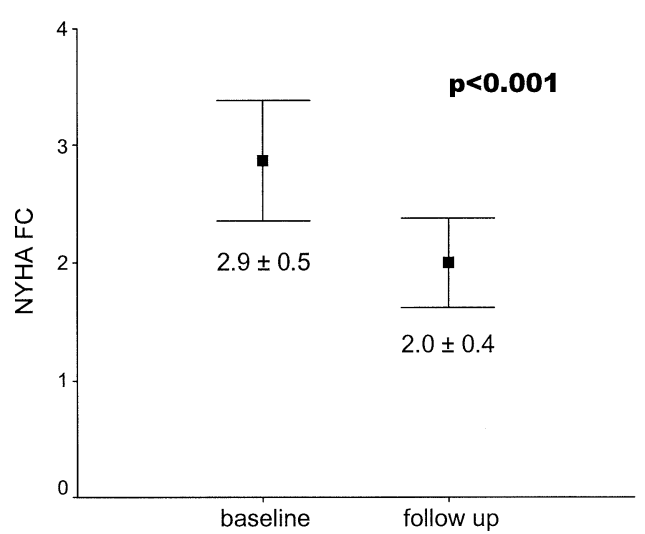

Figure 1. NYHA functional class (mean) before and after surgery ( $n=15$ ). Time of postoperative follow-up varied from 3 months (5 patients) to 12 months (10 patients). No difference was observed between groups. NYHA FC, New York Heart Association functional class.

\section{Results}

\section{LVR Surgery}

The procedure was well tolerated in all 15 patients. Before LVR surgery, 3 patients were in NYHA functional class II, 11 patients in class III, and 1 patient in class IV. NYHA class improved in 13 patients whereas 2 patients had no change (1 patient in class I, 13 patients in class II, and 1 patient in class III $[P=.001]$; Figure 1). Medical heart failure treatment was similar to preoperative therapy (Table 1 ); routine laboratory tests did not detect hepatic or renal dysfunction in any patient.

\section{Function}

EF increased from $23.9 \% \pm 6.6 \%$ to $36.2 \% \pm 6.2 \%(P=$ .003) (Table 3). LVEDVI and LVESVI decreased from $140.8 \pm 33.8 \mathrm{~mL} / \mathrm{m}^{2}$ to $90.6 \pm 18.3 \mathrm{~mL} / \mathrm{m}^{2}(P=.005)$ and from $107.6 \pm 30.9 \mathrm{~mL} / \mathrm{m}^{2}$ to $57.6 \pm 12.7 \mathrm{~mL} / \mathrm{m}^{2}(P=$ $.003)$, respectively. Mitral regurgitation, present preoperatively in 5 patients, was also decreased. There was no difference in EF, LVEDVI, or LVESVI between the 10 patients followed for 12 months and the 5 patients followed for 3 months, confirming our previous observation that improvement of LV function evolved intraoperatively/early postoperatively and was sustained late after LVR. ${ }^{16}$

\section{Neurohormones}

Plasma levels of NE, PRA, A-II, and BNP significantly improved after LVR (Table 4). Median NE decreased from $562 \mathrm{pg} / \mathrm{mL}$ to $319 \mathrm{pg} / \mathrm{mL}(P<.05)$. Median PRA and median A-II dropped from $5.7 \mu \mathrm{g} / \mathrm{L} / \mathrm{h}$ to $3.4 \mu \mathrm{g} / \mathrm{L} / \mathrm{h}(P<$ $.05)$ and from $41 \mathrm{ng} / \mathrm{mL}$ to $23 \mathrm{ng} / \mathrm{mL}(P=.051)$, respectively. Median BNP decreased from $771 \mathrm{pg} / \mathrm{mL}$ to 266 $\mathrm{pg} / \mathrm{mL}(P<.05)$. Figure 2 depicts the course of NE, PRA, and A-II in each patient.
The changes of pre- to postoperative PRA and A-II inversely correlated with the change of EF. The more PRA decreased after surgery, the higher the increase of $\mathrm{EF}(R=$ $-.745, P<.05)$. A similar association was found between the decrease of A-II and the increase of EF $(R=-.808, P$ $<$.05). Furthermore, the decrease of BNP correlated with the decrease of LVEDVI with a trend toward significance $(R$ $=.846, P=.071)$. No association was found between changes of NE and changes of EF, LVEDVI, or LVESVI.

\section{Discussion}

\section{Neuroendocrine Activation in $\mathbf{C H F}$}

Neurohormones participate in many pathologic adaptations and can contribute to the progression of CHF. ${ }^{17}$ Medical therapy that decreases neuroendocrine activation also reduces the mortality of $\mathrm{CHF}^{9,10,18}$ and may correlate with modest improvements of $\mathrm{EF}$ and functional parameters. ${ }^{19-21}$ However, neurohormonal models may be necessary but are not sufficient to explain all aspects of disease progression in $\mathrm{CHF}^{22}$ Neurohormones are not deranged without a triggering event; thus the elimination of 1 trigger (eg, surgical reduction of pathologic cardiac wall stress) may result in the reduction of neurohormones. In support of this, lowering cardiac filling pressure alone by diuretics and vasodilators can rapidly suppress the neurohumoral activation in decompensated heart failure with decreased BNP and NE profiles. $^{23}$

\section{Neurohormonal Response to Surgical Intervention}

In this study, we observed improvement in neurohormones that may be attributed to surgical improvement of LV anatomy with increase of EF and decrease of LV volume and mitral regurgitation. Importantly, although LVR was an aspect of additional procedures (eg, CABG or MVR), the impact of each individual surgical therapy on the improvement of neurohormones cannot be determined because all associated aspects of ischemic cardiomyopathy were repaired. We and others ${ }^{24,25}$ advocate a complete revascularization whenever possible to achieve an optimal result after LVR. Valve repair, if necessary, is also indicated to realize the full benefit of this procedure. ${ }^{26} \mathrm{We}$ expect that the favorable neurohormonal response observed in this study may have been generated by the combined surgical strategy. ${ }^{27}$

In agreement with the current study, atrial natriuretric peptide (ANP) and BNP profiles were significantly lowered after revascularization in ischemic cardiomyopathy concurrent with an improvement of LV function and NYHA functional class. ${ }^{28}$ We have previously shown that the insertion of an LV assist device in patients with decompensated CHF was followed by significantly improved NE, PRA, and A-II profiles, concomitant with partial recovery of the native heart. ${ }^{29}$ Furthermore, preoperatively elevated plasma ANP levels normalized after mitral valve surgery for degenera- 
TABLE 3. Left ventricular ejection fraction and dimensions, mitral regurgitation $(n=15)^{*}$

\begin{tabular}{|c|c|c|c|c|}
\hline & Preoperative & Postoperative‡ & Mean $\%$ change & $P$ value \\
\hline Ejection fraction $(\%)$ & $23.9 \pm 6.6$ & $36.2 \pm 6.2$ & +51.5 & .003 \\
\hline End-diastolic volume index $\left(\mathrm{mL} / \mathrm{m}^{2}\right)$ & $140.8 \pm 33.8$ & $90.6 \pm 18.3$ & -35.6 & .005 \\
\hline End-systolic volume index $\left(\mathrm{mL} / \mathrm{m}^{2}\right)$ & $107.6 \pm 30.9$ & $57.6 \pm 12.7$ & -46.5 & .003 \\
\hline Mitral regurgitationt (grade) & $2.4 \pm 1.5$ & $0.8 \pm 1.1$ & $\mathrm{~N} / \mathrm{A}$ & .035 \\
\hline
\end{tabular}

*Left ventricular volumes and ejection fraction were assessed by magnetic resonance imaging, real-time 3-dimensional echocardiography, or a combination of both. Magnetic resonance was assessed by 2-dimensional echocardiography.

tData are presented for 5 patients undergoing mitral valve repair.

†Time of postoperative follow-up varied from 3 months (5 patients) to 12 months (10 patients). No difference was observed between groups.

TABLE 4. Neurohormones

\begin{tabular}{|c|c|c|c|c|c|c|}
\hline & \multicolumn{2}{|c|}{ Preoperative } & \multicolumn{2}{|c|}{ Postoperative* $^{*}$} & \multirow{2}{*}{$\begin{array}{c}\text { Mean \% } \\
\text { change }\end{array}$} & \multirow[b]{2}{*}{$P$ value } \\
\hline & Median (n) & Mean $(95 \% \mathrm{CI})$ & Median (n) & Mean $(95 \% \mathrm{Cl})$ & & \\
\hline Norepinephrine $(\mathrm{pg} / \mathrm{mL})(80-520 \mathrm{pg} / \mathrm{mL})$ & $562(10)$ & $616(377 ; 855)$ & $319(10)$ & $406(223 ; 591)$ & -34.0 & .017 \\
\hline $\begin{array}{l}\text { Plasma renin activity }(\mu \mathrm{g} / \mathrm{L} / \mathrm{h})(0.5-1.8 \\
\mu \mathrm{g} / \mathrm{L} / \mathrm{h})\end{array}$ & $5.7(10)$ & $13.6(4.0 ; 23.2)$ & $3.4(10)$ & $4.8(2.0 ; 7.7)$ & -64.7 & .022 \\
\hline Angiotensin II (ng/mL) (10-50 ng/L) & $41(9)$ & $92(0 ; 206)$ & $23(10)$ & $29(14 ; 44)$ & -68.3 & .051 \\
\hline $\begin{array}{l}\text { Brain natriuretric peptide }(\mathrm{pg} / \mathrm{mL}) \\
\qquad(<100 \mathrm{pg} / \mathrm{mL})\end{array}$ & $771(5)$ & $776(373 ; 1178)$ & $266(5)$ & $417(83 ; 750)$ & -46.3 & .043 \\
\hline
\end{tabular}

*Time of postoperative follow-up varied from 3 months (brain natriuretric peptide) to 12 months (norepinephrine, plasma renin activity, angiotensin II).

tive valve disease along with an improvement of functional parameters. ${ }^{30}$

\section{Implications}

The favorable neurohormonal response observed in this study may indicate an improved long-term prognosis after LVR surgery. Patients with a considerable percent decrease in NE (and BNP) profiles may experience a profound decline in mortality. ${ }^{31}$ Further, median NE levels above 393 $\mathrm{pg} / \mathrm{mL}$ were previously found predictive for an increased mortality. ${ }^{32}$ In our study, median NE was significantly reduced to $319 \mathrm{pg} / \mathrm{mL}$, a profile similar to that of a matching cohort of control subjects in the SOLVD trial. ${ }^{3}$ This observation suggests that the mortality of patients with ischemic cardiomyopathy can be significantly reduced by surgery including LVR. In addition, depressed EF $(<30 \%)$ and increased LVESVI $\left(>70 \mathrm{~mL} / \mathrm{m}^{2}\right)$ were associated with an increased mortality of patients with myocardial infarction ${ }^{33}$ and CHF. ${ }^{34}$ In this study, baseline EF and LVESVI were even more compromised; thus, the improvement of both parameters by LVR surgery to $36.2 \% \pm 6.2 \%$ and $57.6 \pm$ $12.7 \mathrm{~mL} / \mathrm{m}^{2}$, respectively, may also prognosticate a better long-term survival. Moreover, PRA and A-II profiles, both markedly reduced by LVR in this study, were elevated in patients with poor LV function and overt $\mathrm{CHF}^{3,35}$ Accordingly, we found an inverse correlation between changes of PRA and A-II profiles with changes of EF in the current study. Furthermore, the decrease of BNP profiles after LVR in this study may not only be predictive of a reduced mortality ${ }^{6,7,31,36}$ but may also indicate the suppression of a trigger of neuroendocrine activation. In agreement with the current study, previous reports have shown that BNP is related to $\mathrm{LVEDVI}^{36}$ and the reduction of intracardiac filling pressure decreases BNP profiles. ${ }^{23}$ Reduction of cardiac wall stress may possibly contribute to the decreased neuroendocrine activation after LVR.

\section{Study Limitations}

This study analyzed the effect of LVR surgery on neuroendocrine activation in a small number of patients. Importantly, the improvement of LV function in the patients studied is in close agreement with previous reports of larger cohorts of patients from our institution ${ }^{12-16}$ and elsewhere, ${ }^{11}$ indicating that the patients enrolled in this study are indeed representative. Continued medical therapy, while unchanged from preoperative therapy, may have contributed to the improvement of neurohormones in addition to the surgical therapy.

Another limitation arises from the different lengths of follow-up in the 5 patients with BNP profiles in comparison with the remaining 10 patients with other neurohormone data. Of note, improvements of LV function and NYHA classification did not differ between groups, suggesting that the trigger of the neurohormonal response was similar and, hence, the course of neurohormone profiles were likely comparable. LV redilation years after surgery may be possible and could lead to reactivation of neurohormones with consecutive decrease of prognosis. 
Norepinephrine

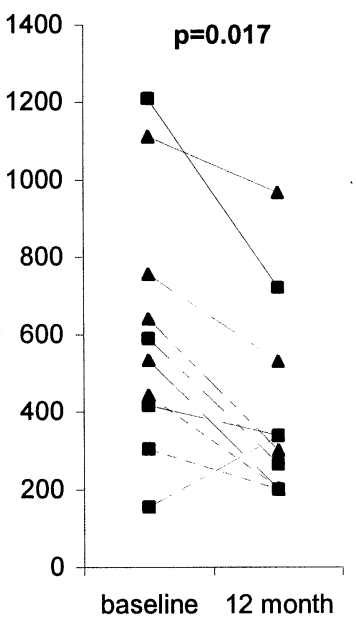

Angiotensin II

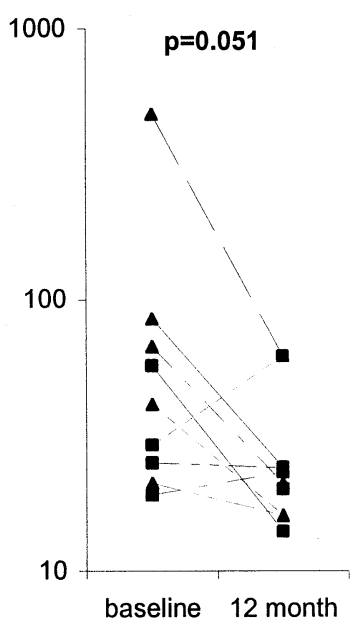

Plasma renin activity

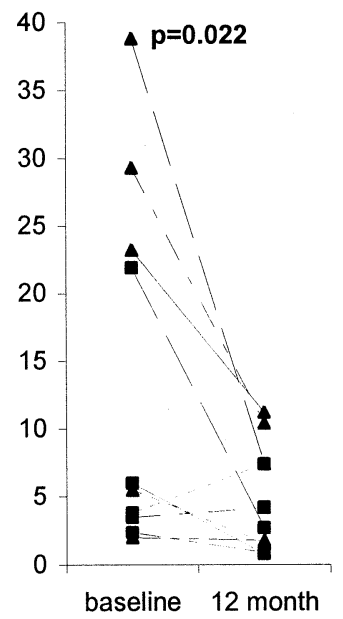

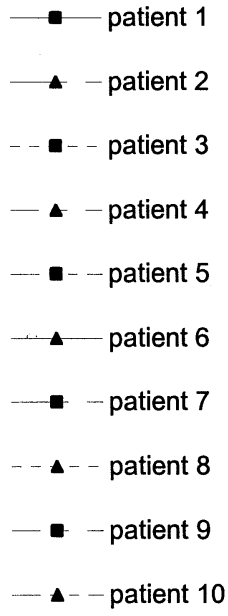

Figure 2. NE, A-II, and PRA profiles before and after surgery $(n=10)$. Considerable improvements of neurohormones were observed during follow-up. Of note, patient 6 experienced only a modest decrease of norepinephrine, corresponding to an improvement of NYHA class IV before surgery to class III at 1 year after surgery.

\section{Conclusions}

LVR surgery was accompanied by a favorable neurohormonal response. Decreased profiles of selected neurohormones were associated with improved LV function. These results support the hypothesis that direct improvement of cardiovascular function may reduce neuroendocrine activation by removing trigger mechanisms. Because neuroendocrine activation is of prognostic significance in CHF, the favorable neurohormonal response after LVR surgery may be indicative of an improved long-term survival. Further studies are necessary to confirm this prediction.

The authors thank Ms Adelaide Jaffe for editorial advice.

\section{References}

1. Gheorghiade M, Bonow RO. Chronic heart failure in the United States: a manifestation of coronary artery disease. Circulation. 1998;97:282-9.

2. Zardini P, Marino P, Golia G, Anselmi M, Castelli M. Ventricular remodeling and infarct expansion. Am J Cardiol. 1993;72:98G-106G.

3. Francis GS, Benedict C, Johnstone DE, Kirlin PC, Nicklas J, Liang $\mathrm{CS}$, et al. Comparison of neuroendocrine activation in patients with left ventricular dysfunction with and without congestive heart failure. A substudy of the Studies of Left Ventricular Dysfunction (SOLVD). Circulation. 1990;82:1724-9.

4. Francis GS, Cohn JN, Johnson G, Rector TS, Goldman S, Simon A. Plasma norepinephrine, plasma renin activity, and congestive heart failure. Relations to survival and the effects of therapy in V-HeFT II. The V-HeFT VA Cooperative Studies Group. Circulation. 1993;87: VI40-8.

5. Francis GS, Goldsmith SR, Levine TB, Olivari MT, Cohn JN. The neurohumoral axis in congestive heart failure. Ann Intern Med. 1984; 101:370-7.

6. Omland T, Aakvaag A, Bonarjee VV, Caidahl K, Lie RT, Nilsen DW, et al. Plasma brain natriuretric peptide as an indicator of left ventricular systolic function and long-term survival after acute myocardial infarction. Comparison with plasma atrial natriuretric peptide and N-terminal proatrial natriuretric peptide. Circulation. 1996;93:1963-9.

7. Tsutamoto T, Wada A, Maeda K, Hisanaga T, Maeda Y, Fukai D, et al. Attenuation of compensation of endogenous cardiac natriuretic peptide system in chronic heart failure. Prognostic role of plasma brain natriuretic peptide concentration in patients with chronic symptomatic left ventricular dysfunction. Circulation. 1997;96:509-16.

8. Morrow DA, de Lemos JA, Sabatine MS, Murphy SA, Demopoulos LA, DiBattiste PM, et al. Evaluation of B-type natriuretic peptide for risk assessment in unstable angina/non-ST-elevation myocardial infarction. B-type natriuretic peptide and prognosis in TACTICS-TIMI 18. J Am Coll Cardiol. 2003;41:1264-72.

9. The SOLVD Investigators. Effects on enalapril on survival in patients with reduced left ventricular ejection fraction and congestive heart failure. N Engl J Med. 1991;325:293-302.

10. Packer M, Coats AJ, Fowler MB, Katus HA, Krum H, Mohacsi P, et al. Effect of carvedilol on survival in severe chronic heart failure. N Engl J Med. 2001;344:1651-8.

11. Athanasuleas CL, Stanley AW Jr, Buckberg GD, Dor V, DiDonato M, Blackstone EH. Surgical anterior ventricular endocardial restoration (SAVER) in the dilated remodeled ventricle after anterior myocardial infarction. RESTORE group. Reconstructive Endoventricular Surgery, returning Torsion Original Radius Elliptical Shape to the LV. J Am Coll Cardiol. 2001;37:1199-209.

12. Shiota T, McCarthy PM, White RD, Qin JX, Greenberg NL, Flamm $\mathrm{SD}$, et al. Initial clinical experience of real-time three-dimensional echocardiography in patients with ischemic and idiopathic dilated cardiomyopathy. Am J Cardiol. 1999;84:1068-73.

13. Qin JX, Jones M, Shiota T, Greenberg NL, Tsujino H, Firstenberg MS, et al. Validation of real-time three-dimensional echocardiography for quantifying left ventricular volumes in the presence of a left ventricular aneurysm: in vitro and in vivo studies. J Am Coll Cardiol. 2000;36:900-7.

14. Caldeira C, McCarthy PM. A simple method of left ventricular reconstruction without patch for ischemic cardiomyopathy. Ann Thorac Surg. 2001;72:2148-9.

15. Shiota T, McCarthy PM. Volume reduction surgery for end-stage ischemic heart disease. Echocardiography. 2002;19:605-12.

16. Qin JX, Shiota T, McCarthy PM, Firstenberg MS, Greenberg NL, Tsujino H, et al. Real-time three-dimensional echocardiography study 
of left ventricular function after infarct exclusion surgery for ischemic cardiomyopathy. Circulation. 2000;102:III101-6.

17. Packer M. The neurohormonal hypothesis: a theory to explain the mechanism of disease progression in heart failure. J Am Coll Cardiol. 1992;20:248-54.

18. Goldstein S, Fagerberg B, Hjalmarson A, Kjekshus J, Waagstein F, Wedel $\mathrm{H}$, et al. Metoprolol controlled release/extended release in patients with severe heart failure: analysis of the experience in the MERIT-HF study. J Am Coll Cardiol. 2001;38:932-8.

19. McKelvie RS, Yusuf S, Pericak D, Avezum A, Burns RJ, Probstfield $\mathrm{J}$, et al. Comparison of candesartan, enalapril, and their combination in congestive heart failure: randomized evaluation of strategies for left ventricular dysfunction (RESOLVD) pilot study. The RESOLVD Pilot Study Investigators. Circulation. 1999;100:1056-64.

20. The RESOLVD Investigators. Effects of metoprolol CR in patients with ischemic and dilated cardiomyopathy: the randomized evaluation of strategies for left ventricular dysfunction pilot study. Circulation. 2000;101:378-84.

21. Cohn JN, Ferrari R, Sharpe N. Cardiac remodeling-concepts and clinical implications: a consensus paper from an international forum on cardiac remodeling. Behalf of an International Forum on Cardiac Remodeling. J Am Coll Cardiol. 2000;35:569-82.

22. Mann DL. Mechanisms and models in heart failure: a combinatorial approach. Circulation. 1999;100:999-1008.

23. Johnson W, Omland T, Hall C, Lucas C, Myking OL, Collins C, et al. Neurohormonal activation rapidly decreases after intravenous therapy with diuretics and vasodilators for class IV heart failure. $\mathrm{J} \mathrm{Am} \mathrm{Coll}$ Cardiol. 2002;39:1623-9.

24. Jatene AD. Left ventricular aneurysmectomy: resection or reconstruction. J Thorac Cardiovasc Surg. 1985;89:321-31.

25. Dor V, Sabatier M, Di Donato M, et al. Late hemodynamic results after left ventricular patch repair associated with coronary grafting in patients with postinfarction akinetic or dyskinetic aneurysm of the left ventricle. J Thorac Cardiovasc Surg. 1995;110:1291-301.

26. Qin JX, Shiota T, McCarthy PM, Asher CR, Hail M, Agler DA, et al. Importance of mitral valve repair associated with left ventricular reconstruction for patients with ischemic cardiomyopathy: a real-time three-dimensional echocardiographic study. Circulation. 2003; 108(Suppl 1):II241-6.

27. McCarthy PM. Synergistic approaches in the surgical treatment of heart failure: complex solutions for complex problems. Semin Thorac Cardiovasc Surg. 2002:187-9.

28. Chello M, Mastroroberto P, Perticone F, Cirillo F, Bevacqua E, Olivito $\mathrm{S}$, et al. Plasma levels of atrial and brain natriuretric peptides as indicators of recovery of left ventricular systolic function after coronary artery bypass. Eur J Cardiothorac Surg. 2001;20:140-6.

29. James KB, McCarthy PM, Thomas JD, Vargo R, Hobbs RE, Sapp S, et al. Effect of the implantable left ventricular assist device on neuroendocrine activation in heart failure. Circulation. 1995;92:II191-5.

30. Nakamura M, Chiba M, Ueshima K, Arakawa N, Yoshida H, Makita $\mathrm{S}$, et al. Effects of mitral and/or aortic valve replacement or repair on endothelium-dependent peripheral vasorelaxation and its relation to improvement in exercise capacity. Am J Cardiol. 1996;77:98-102.

31. Le Tourneau T, de Groote P, Millaire A, Foucher C, Savoye C, Pigny $\mathrm{P}$, et al. Changes in brain natriuretic peptide and norepinephrine over time and mortality and morbidity in the Valsartan Heart Failure Trial (Val-HeFT). Circulation. 2003;107:1278-83.

32. Benedict CR, Shelton B, Johnstone DE, Francis G, Greenberg B, Konstam M, et al. Prognostic significance of plasma norepinephrine in patients with asymptomatic left ventricular dysfunction. Circulation. 1996;94:690-7.

33. Burns RJ, Gibbons RJ, Yi Q, Roberts RS, Miller TD, Schaer GL, et al. The relationships of left ventricular ejection fraction, end-systolic volume index and infarct size to six-month mortality after hospital discharge following myocardial infarction treated by thrombolysis. J Am Coll Cardiol. 2002;39:30-6.

34. Smith GL, Masoudi FA, Vaccarino V, Radford MJ, Krumholz HM. Outcomes in heart failure patients with preserved ejection fraction. Mortality, readmission, and functional decline. J Am Coll Cardiol. 2003; $41: 1510-8$

35. Eriksson SV, Eneroth P, Kjekshus J, Offstad J, Swedberg K. Neuroendocrine activation in relation to left ventricular function in chronic severe congestive heart failure: a subgroup analysis from the Cooperative North Scandinavian Enalapril Survival Study (CONSENSUS). Clin Cardiol. 1994;17:603-6.

36. Stanek B, Frey B, Hulsmann M, Berger R, Sturm B, Strametz-Juranek $\mathrm{J}$, et al. Prognostic evaluation of neurohumoral plasma levels before and during beta-blocker therapy in advanced left ventricular dysfunction. J Am Coll Cardiol. 2001;38:436-42. 